\title{
Relevance of Twin Deficit Hypotheses: An Econometric Analysis with Reference to India
}

\author{
Suresh K.G. ${ }^{1}$, Vikas Gautam ${ }^{2}$ \\ ${ }^{1}$ Department of Economics, IBS, Hyderabad, India \\ ${ }^{2}$ IBS Gurgaon, Gurgaon, India \\ Email: sureshkg@ibsindia.org, vgautam78@gmail.com
}

Received 25 March 2015; accepted 19 April 2015; published 22 April 2015

Copyright (C 2015 by authors and Scientific Research Publishing Inc.

This work is licensed under the Creative Commons Attribution International License (CC BY). http://creativecommons.org/licenses/by/4.0/

(c) (i) Open Access

\begin{abstract}
Current study examines the relevance of twin deficit hypothesis in Indian context by considering the endogenously determined structural breaks in both unit root and cointegration tests. The cointegration analysis shows that there is no long term relationship between the study variables. But the Granger causality test results indicate that bidirectional granger causality is running between the variables. Results showed no long run relationship between the variables; twin divergence in the long run, while in the short term, variables are related. The findings of the study are based on data for the period 1973-1974 to 2013-2014.
\end{abstract}

\section{Keywords}

Current Account Deficit, Fiscal Deficit, Granger-Causality Test, Cointegration Test

\section{Introduction}

Economic theory provides different views on the relationship between budget and current account deficit. The Keynesian economists are of the view that the budget and current account deficits are related and an increase in fiscal shocks will make the current account balance worst. On the other hand, the Ricardian Equivalence Hypothesis (REH) postulates that these two variables are not related. The Keynesian view supports the popular hypothesis known as "Twin deficit hypothesis, while the Ricardian view is in favour of twin divergence hypothesis.

Over the years many researchers have tested the validity of both the views on current account and fiscal deficit in different origins of contexts by using different econometric methodologies. But these studies did not pro- 
vide conclusive evidence on the issue. This topic is now attracting the attention of the researchers, since many countries face the problem of high fiscal deficit in the context of the stimulus packages to fight the recent economic crisis [1] [2]. Will this high level of fiscal deficit cause deficit in external account? In this study, we are addressing this issue in the context of a developing country: India. India provides a suitable platform for analysing this issue, since it experiences deficits in both current account and budget account since 1960s. To maintain fiscal stability in central and state budgets, the Indian parliament passed the Fiscal Responsibility and Budget Management Act 2004, which aimed at reducing the fiscal deficit to 3\% of GDP and eliminating the revenue deficit by 2008-2009. But recently it experiences a fiscal deficit of more than 6\% of GDP (Fiscal deficit of Central government) for the years 2008-2009 and 2009-2010 (Economic survey 2011, Govt. of India) and 5.1\% in 2010-2011. The rise in the fiscal deficit of the government of India in the last three years is mainly due to the stimulus packages announced to fight the global slowdown in the economy.

Therefore, the objective of current study is to examine the relevance of twin deficit hypothesis in Indian context by considering the endogenously determined structural breaks in both unit root and cointegration tests. The issue of structural breaks in the estimation of unit root test and cointegration analysis has been ignored in the literature especially in Indian context and in this study, we have considered the possible breaks in both unit root as well as cointegration analysis. For considering the structural breaks in unit root test, we have used a recently developed [3] unit root test, while for cointegration we used the [4] cointegration tests. The study found that the $\mathrm{CAD}$ and FD in India are not cointegrated; no long term relationship exists between the variables. But we found bidirectional causality between the study variables in the short term.

\section{Analytical Framework}

Here we present a connection between budget deficit and current account balance that might be traced from the national income identity,

$$
Y=C+I+G+(X-M)
$$

where $Y, C, I, G, X$ and $M$ denotes national income, consumption expenditure, investment spending, government expenditure, exports and imports of goods and services respectively. Here we can define current account (CA) balance as:

$$
C A=(X-M)+N I T F
$$

where NITF stands for net income and transfer flows (that is income received from abroad or paid abroad and unilateral transfers) and it is added to the net balance from goods and services flows. However, if we assume for simplicity, that NITF are not large enough to affect CA significantly or proportion of NITF is negligible therefore, we can omit this variable and our CA will be just equal to trade balance.

Further, national savings $(S)$ in an open economy based on the national income identity, can be written as follows:

$$
S=Y-C-G+C A
$$

Alternatively, we can write the above equation as:

$$
S=I+C A
$$

where $I=Y-C-G$, and $I$ stands for investment spending. Further, we can subgroup national saving between saving decisions made by the private sector $(S p)$ and saving decisions made by the government $(S g)$ and therefore, mathematically, we have,

$$
S=S p+S g
$$

Since, $(S p)$ is that part of personal disposable income (i.e. income after tax) that is saved rather than consumed and therefore, we can write $(S p)$ as:

$$
S p=Y d-C=(Y-T)-C
$$

where $Y d$ personal disposable income and $T$ is tax collected by the government. Further, we define government saving $(\mathrm{Sg})$ as difference between government revenue collected in the form of taxes $(T)$ and expenditures that is done in form of government purchases $(G)$ and government transfers $(R)$ and hence, mathematically, 
we have:

$$
S g=T-(G+R)=T-G-R
$$

Hence, Equation (5) in an identity form can be written as:

$$
S=S p+S g=(Y-T-C)+(T-G-R)=I+C A
$$

Further, we can modify Equation (8) as follows if we allow the effects of government saving decisions in an open economy:

$$
S p=I+C A-S g=I+C A-(T-G-R)
$$

Or alternatively we can write Equation (8) as:

$$
C A=S p-I-(G+R-T)
$$

where the term in parenthesis is consolidated public sector budget deficit (BDEF), that is, as government saving preceded by a minus sign. The government deficit measures the extent to which the government is borrowing to finance its expenditures. Equation (9) states that a country's private savings can take three forms: investment in domestic capital (I), purchases of wealth from foreigners (CA), and purchases of the domestic government's newly issued debt $(G+R-T)$.

Looking at the macroeconomic identity (10), we can see that two extreme cases are possible. If we assume that difference between private savings and investment is stable over time, the fluctuations in the public sector deficit will be fully translated to current account and the twin deficits hypothesis will hold. The Public sector includes general government (local and central) and non-financial public enterprises (state enterprises like railroads, public utility and other nationalized industries). The second extreme case is known as Ricardian Equivalence Hypothesis, which assumes that change in the budget deficit will be fully offset by change in savings. The explanation is the following; a tax cut does not affect households' lifetime wealth because future taxes will go up to compensate for the current tax decrease. So, current private households save the income received from the tax cut in order to pay for the future tax increase. Hence, a budget deficit would not cause a twin deficit.

\section{Literature Survey}

Although there are so many studies in the literature on twin deficit hypothesis, there hardly exists any consent. Here we are reviewing some past literature to get clarity of concept and state of research in the concerned field of knowledge.

Those studies supporting the twin deficit hypothesis includes, inter alia, [5]-[15] whose that the twin deficit hypothesis is valid and the budget deficit is causing the trade deficit significantly. But, several studies have rejected the twin deficit hypothesis, inter alia, [16]-[20]. While [21] found long term relationship between fiscal deficit and current account deficit for developing countries; for developed countries they didn't find any long term relationship between fiscal deficit and current account deficit [22].

In the context of India one of the first systematic study in this area was of [23], who used a VAR framework to address the twin deficit issue and found that a causal relationship running from Current account deficit to Fiscal deficit, but they didn't examine the long term relationship between the variables. [21] analyzed the cointegration between the deficit variables in Indian context; found that the Twin deficit hypothesis is valid. But by using quarterly data for the period 1985 to 2001, [24] found that the twin deficit hypothesis is not holding in Indian context. This is contradicting to [25], who found that opposite to the findings of [23], causality, is running from fiscal deficit to current account and both the variables are related in the long term for the period 1970-71 to 1999-2000 using annual data. Recently [26] examined the issue employing the bond test of cointegration for the period 1998 to 2009 using monthly data. Ratha found that the twin deficit hypothesis is valid only in the short term, while the Ricardian Equivalence Hypothesis (REH) holds in the long term.

The current literature on this issue especially in Indian context provides contradicting results on the effect of fiscal deficit on current account deficit. Secondly, to the best of our knowledge, none of the above mentioned studies considered the effect of structural breaks while analyzing cointegration analysis between budget deficit and current account deficit. Our main contribution in this study is considering the endogenously determined structural breaks in both unit root analysis and cointegration. 


\section{Data and Methodology}

We have used the Current account and Gross Fiscal deficit as percentage of GDP for the period 1973-1974 to 2013-2014. This data is available in the Reserve Bank of India (RBI) website.

Since the study period is long and during this period India experienced many economic policy changes such as the economic reforms in the year of 1991, which includes reforms in external as well as domestic sectors of the economy. Therefore, it is appropriate to consider the possible structural breaks in estimating the unit root test. [27] observed that ignoring structural breaks in DF test can lead to the false acceptance of the unit root null hypothesis. [28] developed a unit root test which considers one endogenously determined structural break, but this test is severely criticised by [29] [30] observed that the ADF type tests like ZA and LP test identifies the break point one period prior to the true break point (i.e., $T B_{t-1}$ rather than $\mathrm{TB}$ ) and the bias in estimating the persistence parameter is maximized and spurious rejections are the greatest. [29] [30] solved this problem by developing minimum Lagrange Multiplier (LM) unit root tests with one break and two breaks. However [31] observed that the reasons for spurious regression are the different interpretations of test parameter under null and alternative hypothesis, since the parameters have implications for the selection of the break date.

But, here we are using a recent unit root test developed by [3], which solved the problems in ADF type test, for the case of Innovational Outlier (IO), where the Data Generating Process is formulated as an unobserved component model. [30] claim that in their new test "critical values (CVs) of the test, assuming unknown break dates, converge with increasing sample size to the CVs when break points are known".

[30] have defined the test as follows. Suppose, we consider an unobserved components model to represent the DGP and the DGP of the time series $y_{t}$ has two components, a deterministic component $\left(d_{t}\right)$ and a stochastic component $\left(u_{t}\right)$, as follows:

$$
\begin{gathered}
y_{t}=d_{t}+u_{t}, \\
u_{t}=\rho u_{t-1}+\varepsilon_{t}, \\
\varepsilon_{t}=\Psi^{*}(L) e_{t}=A^{*}(L)^{-1} B(L) e_{t},
\end{gathered}
$$

$e_{t}$ is a white noise process, such that $e_{t} \sim \operatorname{NIID}\left(0, \sigma^{2}\right)$. By assuming that the roots of the lag polynomials $A^{*}(L)$ and $B(L)$, which are of order $p$ and $q$, respectively, lie outside the unit circle [30] considered two different specifications for trending data-one allows for two breaks in level (denoted as model 1 i.e., M1) and the other allows for two breaks in level as well as slope (denoted as model 2 i.e., M2). The specification of both models differs in terms of the definition of the deterministic component, $d_{t}$ :

$$
\begin{gathered}
d_{t}^{M 1}=\alpha+\beta t+\Psi^{*}(L)\left(\theta_{1} D U_{1, t}^{\prime}+\theta_{2} D U_{2, t}^{\prime}\right), \\
d_{t}^{M 2}=\alpha+\beta t+\Psi^{*}(L)\left(\theta_{1} D U_{1, t}^{\prime}+\theta_{2} D U_{2, t}^{\prime}+\gamma_{1} D T_{1, t}^{\prime}+\gamma_{2} D T_{2, t}^{\prime}\right), \\
\text { With } D U_{i, t}^{\prime}=1\left(t>T_{B, i}^{\prime}\right), D T_{i, t}^{\prime}=1\left(t>T_{B, i}^{\prime}\right)\left(t-D T_{B, i}^{\prime}\right), i=1,2 .
\end{gathered}
$$

where, $T_{B, i}^{\prime}, i=1,2$, denote the true break dates, $\theta_{i}$ and $\gamma_{i}$, indicate the magnitude of the level and slope breaks, respectively. The inclusion of $\Psi^{*}(L)$ in Equation (3) enables the breaks to occur slowly over time i.e., it assumes that the series responds to shocks to the trend function the way it reacts to shocks to the innovation process $e_{t}$ [32]. This process is known as the IO model and the IO-type test regressions to test for the unit root hypothesis for M1 and M2 can be derived by merging the structural model (11)-(15). The test regressions can be derived from the corresponding structural model in reduced form as follows:

$$
y_{t}^{M 1}=\rho y_{t-1}+\alpha_{1}+\beta^{*} t+\theta_{1} D\left(T_{B}^{\prime}\right)_{1, t}+\theta_{2} D\left(T_{B}^{\prime}\right)_{2, t}+\delta_{1} D U_{1, t-1}^{\prime}+\delta_{2} D U_{2, t-1}^{\prime}+\sum_{j=1}^{k} \beta_{j} \Delta y_{t-j}+e_{t},
$$

with $\alpha_{1}=\Psi^{*}(1)^{-1}[(1-\rho) \alpha+\rho \beta]+\Psi^{* \prime}(1)^{-1}(1-\rho) \beta, \Psi^{* \prime}(1)^{-1}$ being the mean lag,

$$
\begin{gathered}
\beta^{*}=\Psi^{*}(1)^{-1}(1-\rho) \beta, \phi=\rho-1, \delta_{i}=-\phi \theta_{i} \text { and } D\left(T_{B}^{\prime}\right)_{i, t}=1\left(t=T_{B, i}^{\prime}+1\right), i=1,2 . \\
y_{t}^{M 2}=\rho y_{t-1}+\alpha^{*}+\beta^{*} t+\kappa_{1} D\left(T_{B}^{\prime}\right)_{1, t}+\kappa_{2} D\left(T_{B}^{\prime}\right)_{2, t}+\delta_{1}^{*} D U_{1, t-1}^{\prime} \\
+\delta_{2}^{*} D U_{2, t-1}^{\prime}+\gamma_{1}^{*} D T_{1, t-1}^{\prime}+\gamma_{2}^{*} D T_{2, t-1}^{\prime}+\sum_{j=1}^{k} \beta_{j} \Delta y_{t-j}+e_{t},
\end{gathered}
$$


where, Equations (13) and (14) are IO-type test regression for M1 and M2 respectively, $\kappa_{i}=\left(\theta_{i}+\gamma_{i}\right), \delta_{i}^{*}=\left(\gamma_{i}-\phi \theta_{i}\right)$, and $\gamma_{i}^{*}=-\phi \gamma_{i}, i=1,2$.

In order to test the unit root null hypothesis of $\rho=1$ against the alternative hypothesis of $\rho<1$, we use the $t$ statistics of $\hat{\rho}$, denoted $t_{\hat{\rho}}$, in Equations (17) and (18).

Since it is assumed that true break dates are unknown, $T_{B, i}^{\prime}$ in Equations (9) and (10) has to be substituted by their estimates $\hat{T}_{B, i}, i=1,2$, in order to conduct the unit root test. The break dates can be selected simultaneously following a grid search procedure or a sequential procedure comparable to [19]. [3] have preferred sequential procedure as because it is far less computationally demanding therefore; we have also followed sequential procedure.

The first step in this case is the search for a single break according to the maximum absolute $t$-value of the break dummy coefficient $\theta_{1}$ for M1 and $\kappa_{1}$ for M2. Thereafter, we impose the restriction $\theta_{2}=\delta_{2}=0$ for M1 and $\kappa_{2}=\delta=\gamma=0$ for M2 and hence, we have:

$$
T_{B, 1}^{\prime}=\left\{\begin{array}{l}
\arg \max _{T_{B, 1}}\left|t_{\hat{\theta}_{1}}\left(T_{B, 1}\right)\right|, \text { for } M 1, \\
\arg \max _{T_{B, 1}}\left|t_{\hat{\kappa}_{1}}\left(T_{B, 1}\right)\right|, \text { for } M 2
\end{array}\right.
$$

So, in the first step, the test procedure reduces to the case described in [31]. Imposing the first break $\hat{T}_{B, 1}$ in the test regression, we estimate the second break date $\hat{T}_{B, 2}$. Again we maximize the absolute t-value; this time $\theta_{2}$ for M1 and $\kappa_{2}$ for M2. Hence, we have:

$$
T_{B, 1}^{\prime}=\left\{\begin{array}{l}
\arg \max _{T_{B, 2}}\left|t_{\hat{\theta}_{2}}\left(\hat{T}_{B, 1}, T_{B, 2}\right)\right|, \text { for } M 1, \\
\arg \max _{T_{B, 2}}\left|t_{\hat{\kappa}_{2}}\left(\hat{T}_{B, 1}, T_{B, 2}\right)\right|, \text { for } M 2
\end{array}\right.
$$

\subsection{Cointegration Test}

After determining the order of integration of each variable, we tested for cointegration to find out whether any long-run relationship exists between the variables (if cointegration exists, it will imply the sustainability of trade). Standard cointegration techniques are biased towards accepting the null of no cointegration and if there is a structural break in the relationship as [20] mentioned that these tests may produce "spurious cointegration results". Further, test based on exogenously determined structural breaks also may not provide fruitful results. Therefore, we applied the [4] cointegration procedure that allows for an endogenously determined structural break in single equation framework. The test presents three models, whereby the shifts can be in either the intercept alone (C):

$$
y_{1 t}=\mu_{1}+\mu_{2} \varphi_{t \tau}+\alpha^{T} y_{2 t}+e_{t}
$$

where $t=1, \cdots, n$.

In both trend and level sift(C/T)

$$
y_{1 t}=\mu_{1}+\mu_{2} \varphi_{t \tau}+\beta t+\alpha^{T} y_{2 t}+e_{t}
$$

And a full shift of the regime shift model(C/S)

$$
y_{1 t}=\mu_{1}+\mu_{2} \varphi_{t i}+\alpha_{1}^{T} y_{2 t}+\alpha_{2}^{T} y_{2 t} \varphi_{t i}+e_{t}
$$

where $t=1, \cdots, n$ and $\mu_{1}, \beta_{1}$ and $\alpha_{1}$ are the intercept, trend and slop coefficients respectively before the regime shift and $\mu_{2}, \beta_{2}$ and $\alpha_{2}$ are the corresponding changes after the break. The dummy variable $\varphi_{t \tau}$ is defined as

$$
\varphi_{t i}= \begin{cases}0, & \text { if } t \leq\{\eta \tau\} \\ 1, & \text { if } t>\{\eta \tau\}\end{cases}
$$

\subsection{Granger Causality Test}

If there is no cointegration between the study variables, we use the Granger Causality test to examine the short 
term casual relationship between the variables. For this we estimate the following equation:

$$
\begin{aligned}
\Delta C A D_{t} & =\alpha_{x}+\sum_{i=1}^{k} \beta_{C A D, i} \Delta C A D_{t-i}+\sum_{i=1}^{k} \gamma_{C A D, i} \Delta F D_{t-i}+\varepsilon_{C A D, t} \\
\Delta F D_{t} & =\alpha_{y}+\sum_{i=1}^{k} \beta_{F D, i} \Delta F D_{t-i}+\sum_{i=1}^{k} \gamma_{C A D, i} \Delta C A D_{t-i}+\varepsilon_{F D, t}
\end{aligned}
$$

The null hypothesis $\left(\mathrm{H}_{0}\right)$ for the Equation (25) is $\mathrm{H}_{0}: \sum^{k} \gamma_{x, i}=0$ suggesting that the lagged terms $\Delta \mathrm{Y}$ do not belong to the regression i.e., it do not Granger cause $\Delta \mathrm{X}$. Conversely, the null hypothesis $\left(\mathrm{H}_{0}\right)$ for the Equation (24) is $H_{0}: \sum \gamma_{y, i}=0$, suggesting that the lagged terms $\Delta \mathrm{X}$ do not belong to regression i.e., it do not Granger cause $\Delta \mathrm{Y}$. The joint test of these null hypotheses can be tested either by F-test or Wald Chi-square $\left(\chi^{2}\right)$ test.

\section{Interpretation of Results}

The unit root test results using [3] procedure are provided in Table 1.

The NP test results indicate that the study variables are nonstationary at level form, since the test statistics are not significant at the conventional significance levels. First differencing of the data series makes it stationary as shown in Table 1, indicating the first order integration of the study variables.

The Gregory-Hanson cointegration test results are given in Table 2 given below. We have estimated three different model; model assuming break in intercept; model assuming break in trend and model assuming break in both trend and constant.

It is evident from the Table 3 that, there are no evidences for a cointegrating relationship between fiscal deficit and current account deficit in the context of India. This result is invariable to the assumption of break in constant or trend or both. The break data identified in Gregory Hanson test is same for the model assuming break in trend and trend and intercept: 1999-2000. But for the first model; assuming break in intercept the break date is 2000-2001.

Since there is no long term relationship between CAD and FD as per the Gregory Hanson cointegration test

\begin{tabular}{|c|c|c|c|c|c|c|}
\hline & \multicolumn{3}{|c|}{ M1 } & \multicolumn{3}{|c|}{ M2 } \\
\hline \multicolumn{7}{|c|}{ At level form } \\
\hline & Test statistic & $1^{\text {st }}$ break & $2^{\text {nd }}$ break & Test statistic & $1^{\text {st }}$ break & $2^{\text {nd }}$ break \\
\hline CAD & $-3.45(2)$ & 2002-2003 & 2004-2005 & $-4.13(4)$ & 2003-2004 & $2004-2005$ \\
\hline FD & $-3.05(2)$ & 2002-2003 & 2004-2005 & $-4.39(4)$ & 2003-2004 & $2004-2005$ \\
\hline \multicolumn{7}{|c|}{ At first difference form } \\
\hline CAD & $-3.37(5)$ & 1979-1980 & 1990-1991 & $-4.989(0)^{* *}$ & 1990-1991 & 1993-1994 \\
\hline FD & $-6.14(0)^{*}$ & 1977-1978 & 1990-1991 & $-6.57(0)^{*}$ & 1980 & $1990-1991$ \\
\hline
\end{tabular}

Table 1. Unit root test results [3].

Note: ${ }^{* *}$ and ${ }^{*}$ indicates significance at $5 \%$ and $1 \%$ level.

Table 2. Gregory Hanson (1996) cointegration test result.

\begin{tabular}{cccc}
\hline Model & Break date & Lags included & T statistics \\
\hline Break in intercept: no trend & $2000-2001$ & 1 & -3.12556 \\
Break in trend & $1999-2000$ & 1 & -3.45266 \\
Trend and intercept & $1999-2000$ & 1 & -3.28418 \\
\hline
\end{tabular}

Note: Critical values are -5.13 and -4.61 for $1 \%$ and $5 \%$ respectively for model with constant. For model with trend, the Critical Values are -5.45 at $1 \%$ level and -4.99 at $5 \%$ level. For model with intercept and trend the respective critical values are -5.47 and -4.95 . Authors' calculation. 
Table 3. Granger causality test result.

\begin{tabular}{ccccc}
\hline Null hypothesis & Lag used & F Statistics & P value & H1 \\
\hline FD does not Granger cause CAD & 1 & 17.34 & 0.002 & FD $\rightarrow$ CAD \\
CAD does not granger cause FD & 1 & 4.42 & 0.04 & CAD $\rightarrow$ FD \\
\hline
\end{tabular}

Note: " $\rightarrow$ " indicates the direction of causality.

result, further we examined the short term casual relationship between the variables using the Granger causality test. The Granger causality test result is sensitive to the no of lags used. We used the lag selection criteria in Eviews 7 to select the lag length for the test. The selection criteria such as SIC, AIC, HQ and LR provide the same result; selecting the first lag.

As shown in the above table the Granger causality test results indicate the presence of a bidirectional causal relationship between the variables.

\section{Conclusions}

We have analyzed the relevance of twin deficit hypothesis in Indian context using the annual data on current account deficit and fiscal deficit for the period 1973-1974 to 2013-2014. We have used a recently developed [3] unit root test to examine the order of integration between the variables. After confirming the same order of integration, we proceed with cointegration analysis to examine the long term relationship between the variables under study. To consider the structural break in cointegration, we have used the [4] cointegration test, which considers one endogenously determined structural break.

The cointegration analysis shows that there is no long term relationship between the study variables. That is current account deficit and fiscal deficit are not related in the long term in Indian context. This is against the postulates of "Twin deficit hypothesis"; which assumes a long term relationship between the study variables. So, our results indicate that in Indian context twin deficit hypothesis is not valid in the long term. But the Granger causality test results indicate that bidirectional granger causality is running between the variables.

Regarding the long run relationship between fiscal deficit and current account deficit, our results are in tandem with the results of [24], who found long term relationship between the variables. But our results are opposite to the results of [25] and [21]. Regarding the short term relationship, we found bidirectional causality between the variables, while [23] noted a unidirectional causality from Current account to fiscal deficit. Our findings are consistent with [26]; twin deficit is not valid in the long run, while in the short run twin deficit hypothesis holds.

\section{References}

[1] Raju, S. and Mukherjee, J. (2010) Fiscal Deficit, Crowding out and the Sustainability of Economic Growth the Case of Indian Economy. Centre for Asian Studies. www.ifri.org/downloads/asievisions31rajumukherjee.pdf

[2] Kumar, R. and Soumya, A. (2010) Fiscal Policy Issues for India after the Global Financial Crisis (2008-2010). ADBI Working Paper Series No. 249. http://dx.doi.org/10.2139/ssrn.1678419

[3] Narayan, P.K. and Popp, S. (2010) A New Unit Root Test with Two Structural Breaks in Level and Slope at Unknown time. Journal of Applied Statistics, 37, 1425-1438. http://dx.doi.org/10.1080/02664760903039883

[4] Gregory, A. and Hansen, B. (1996) Residual-Based Tests for Cointegration in Models with Regime Shifts. Journal of Econometrics, 70, 99-126. http://dx.doi.org/10.1016/0304-4076(69)41685-7

[5] Abell, J.D. (1990) Twin Deficits during the 1980’s: An Empirical Investigation. Journal of Macro Economics, 12, 8196. http://dx.doi.org/10.1016/0164-0704(90)90057-H

[6] Islam, M. (1998) Bazil’s Twin Deficits: An Empirical Examination. Atlantic Economic Journal, 26, 121-129. http://dx.doi.org/10.1007/BF02299354

[7] Zeitiz, J., and Pemberton, D.K. (1990) The US Trade and Budget Deficit: A Simultaneous Equation Model. Southern Economic Journal, 57, 23-34. http://dx.doi.org/10.2307/1060475

[8] Batchman, D.D. (1992) Why Is the US Current Account Deficit So Large: Evidence from Vector Auto Regressions. Southern Economic Journal, 59, 232-240. http://dx.doi.org/10.2307/1060527

[9] Kasa, K. (1994) Finite Horizons and the Twin Deficit. Economic Review, Federal Reserve Bank of Boston, 3, $19-28$.

[10] Vamvoukas, G. (1999) The Twin Deficit Phenomenon: Evidence from Greece. Applied Economics, 31, $1093-1100$. 
http://dx.doi.org/10.1080/000368499323571

[11] Ata, A.Y. and Yucel, F. (2003) Co-Integration and Causality Tests under the Twin Deficits Hypothesis: Application in Turkey. Cukurova University, School of Social Sciences Journal, 12.

[12] Akbostanci, E. and Tunc, G. (2002) Turkish Twin Deficits: An Error Correction Model of Trade Balance. No. 106, ERC Working Papers from ERC—Economic Research Center, Middle East Technical University, Ankara.

[13] Cavello, M. (2005) Government Consumption Expenditures and the Current Account. FRBSF Working Paper. http://www.frbsf.org/economic-research/files/wp05-03bk.pdf

[14] Bussière, M., Fratzscher, M. and Müller, G.J. (2010) Productivity Shocks, Budget Deficits and the Current Account. Journal of International Money and Finance, 29, 1562-1579. http://dx.doi.org/10.1016/j.jimonfin.2010.05.012

[15] Erceg, C.J., Guerreri, L. and Gust, C. (2005) Expansionary Fiscal Shocks and the Trade Deficits. International Finance Discussion Paper No. 2005, Federal Reserve Board.

[16] Enders, W. and Lee, B.S. (1990) Current Account and Budget Deficits: Twin or Distant Cousins? The Review of Economics and Statistics, 72, 373-381. http://dx.doi.org/10.2307/2109344

[17] Boucher, J.L. (1991) The Current Account: A Long and Short Run Empirical Perspective. Southern Economic Journal, 58, 93-111. http://dx.doi.org/10.2307/1060036

[18] Winner, L.E. (1993) The Relationship of the Current Account Balance and the Budget Balance. American Economist, 37, 78-84.

[19] Kustepeli, Y. (2001) An Empirical Investigation of Feldstein Chain for Turkey. DEU, 2, 99-108.

[20] Baharumshah, A., Zubaidi, E.L. and Khalid, A.M. (2005) Testing Twin Deficits Hypothesis: Using VARs and Variance Decomposition. International Finance 0504001, EconWPA.

[21] Khalid, A.M. and Guan, T.W. (1999) Causality Tests of Budget and Current Account Deficits: Cross Country Comparisons. Empirical Economics, 24, 389-402. http://dx.doi.org/10.1007/s001810050062

[22] Piersanti, G. (2000) Current Account Dynamics and Expected Future Budget Deficits: Some International Evidence. Journal of International Money and Finance, 19, 255-271. http://dx.doi.org/10.1016/S0261-5606(00)00004-8

[23] Anoruo, E. and Ramchander, S. (1998) Current Account and Fiscal Deficits: Evidence from Five Developing Economies of Asia. Journal of Asian Economics, 9, 487-501. http://dx.doi.org/10.1016/S1049-0078(99)80099-2

[24] Basu, S. and Datta, D. (2005) Does Fiscal Deficit Influence Trade Deficit? An Econometric Enquiry. Economic and Political Weekly, 40, 3311-3318.

[25] Parikh, A. and Rao, B. (2006) Do Fiscal Deficits Influence Current Accounts? A Case Study of India. Review of Development Economics, 10, 492-505. http://dx.doi.org/10.1111/j.1467-9361.2006.00370.x

[26] Ratha, A. (2012) Twin Deficits or Distant Cousins? Evidence from India. South Asia Economic Journal, 13, 51-68.

[27] Perron, P. (1989) The Great Crash, the Oil Price Shock, and the Unit Root Hypothesis. Econometrica, 57, 1361-1401. http://dx.doi.org/10.2307/1913712

[28] Zivot, E. and Andrews, D.W.K. (1992) Further Evidence on the Great Crash, the Oil-Price Shock, and the Unit-Root Hypothesis. Journal of Business and Economic Statistics, 10, 251-270. http://dx.doi.org/10.2307/1391541

[29] Lee, J. and Strazicich, M. (2004) Minimum LM Unit Root Test with One Structural Break. Working Paper, Department of Economics, Appalachian State University, Boone.

[30] Lee, J. and Strazicich, M.C. (2003) Minimum LM Unit Root Test with Two Structural Breaks. Review of Economics and Statistics, 85, 1082-1089. http://dx.doi.org/10.1162/003465303772815961

[31] Popp, S. (2008) New Innovational Outlier Unit Root Test with a Break at an Unknown Time. Journal of Statistical Computation and Simulation, 78, 1145-1161. http://dx.doi.org/10.1080/00949650701411429

[32] Vogelsang, T.J. and Perron, P. (1998) Additional Tests for a Unit Root Allowing for a Break in the Trend Function at Unknown Time. International Economic Review, 39, 1073-1100. http://dx.doi.org/10.2307/2527353 